\title{
Treatment compliance of self-reported dog bite cases attending outpatient department of Tertiary Care Hospital, Maharashtra
}

\section{Vijay Kishanrao Domple, Mohan K. Doibale, Venkatramana K. Sonkar, Nandkeshav R. Aswar, Hrishikesh A. Khadilkar', Swapnil R. Jain}

Departments of Community Medicine, Dr. Shankarrao Chavan Government Medical College, Nanded, ${ }^{1}$ Government Medical College, Aurangabad, Maharashtra, India

Address for the Correspondence:

Dr. Domple Vijay Kishanrao, Department of Community Medicine, Dr. Shankarrao Chavan Government Medical College, Nanded - 431601 Maharashtra, India.

E-mail: drdigvijay@yahoo.co.in

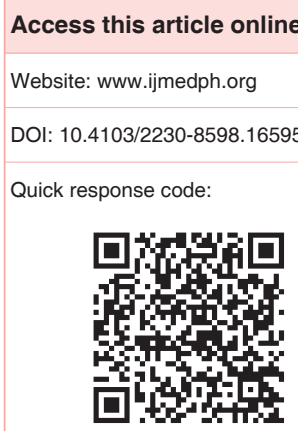

Objectives: To assess treatment compliance of self-reported dog bite cases and to assess associated demographic and exposure factors. Materials and Methods: The present prospective study was conducted during January 2013 to July 2013 among 260 dog bite cases by purposive sampling at the outpatient department of a tertiary hospital. After obtaining verbal informed consent, a predesigned questionnaire was used. The assessment of treatment compliance of postexposure prophylaxis (PEP) regimen was considered on the basis of intramuscular anti-rabies vaccine (ARV) regimen by classifying completed PEP and defaulted PEP. At the end of PEP regimen of every participant, we obtained information about received ARV doses using telephone survey method. Data were analyzed using statistical software Epi info Version 7. Results: Of 260 dog bite cases, $76.5 \%$ cases were completed PEP. The majority, $22.3 \%$ cases from age group $\leq 10$ years, $56.2 \%$ males, $48.1 \%$ from urban area, $25 \%$ had primary school education, $32.7 \%$ students, $53.8 \%$ had bite mark on lower limb, $58.5 \%$ were category III exposure, and $70.8 \%$ who had received previously immunization against rabies, were completed PEP. The bite due to $54.6 \%$ pet dog, $58.1 \%$ observable dog, $40 \%$ provoked bite, $71.9 \%$ cases who had not known about the rabid status of the dog, were completed PEP. The unconditional logistic regression analysis found that demographic and exposure factors were not independently associated with treatment compliance $(P>0.05)$ except literacy status $(P<0.05)$. The present study showed maximum completed PEP cases, however, it showed the demographic and exposure factors of dog bite cases were not independently associated with treatment compliance except literacy status.

Key words: Completed postexposure prophylaxis, defaulted postexposure prophylaxis, dog bite cases, outpatient department, treatment compliance

\section{INTRODUCTION}

Human rabies is endemic in India. ${ }^{[1-3]}$ Rabies virus is usually transmitted by the bite of an infected animal or contamination of broken skin by saliva. ${ }^{[4]}$ The $\operatorname{dog}$ is the principal reservoir of rabies in India. Over $95 \%$ of human deaths due to rabies are caused by dog bites. ${ }^{[5,6]}$ Prevention of rabies is possibly by providing the exposed person with the proper postexposure prophylaxis (PEP), PEP in rabies exposed persons includes wound toilet, postexposure vaccination, and administration of rabies immunoglobulin. ${ }^{[7,8]}$ At the global level, more than 15 million people receive rabies prophylaxis annually, majority of whom live in China and India. It is estimated that in the absence of PEP about 327,000 persons would die from rabies in Africa and Asia each year. ${ }^{[9]}$ At the dawn of $21^{\text {st }}$ century,

This is an open access article distributed under the terms of the Creative Commons AttributionNonCommercial-ShareAlike 3.0 License, which allows others to remix, tweak, and build upon the work non-commercially, as long as the author is credited and the new creations are licensed under the identical terms.

For reprints contact: reprints@medknow.com

How to cite this article: Domple VK, Doibale MK, Sonkar VK, Aswar NR, Khadilkar HA, Jain SR. Treatment compliance of self-reported dog bite cases attending outpatient department of Tertiary Care Hospital, Maharashtra. Int J Med Public Health 2015;5:297-300. 
we have achieved treatments progress in many spheres including science and technology, information technology, agriculture, satellite communication, etc. Unfortunately, we still have the highest number of deaths due to rabies, ironically a disease preventable by modern prophylactic measures. ${ }^{[10]}$ The reasons given for not reporting, completing, or adhering to PEP include poor awareness about the danger of the disease, small size of the injury, reluctance of the dog owner to pay for treatment costs, and not being advised to take PEP. Rabies remains a neglected disease in terms of policy formulations throughout most of the developing countries. ${ }^{[11]}$ Among the various measures recommended for rabies control in dogs such as control of stray dogs and mass education, vaccination constitutes the most effective way to interrupt the rabies transmission cycle. ${ }^{[12]}$

Literature search regarding the same issue showed that very few studies $^{[11-16]}$ was conducted. Keeping in mind, the public health scenario of rabies, this study was undertaken to assess treatment compliance of self-reported dog bite cases and to assess associated demographic and exposure factors.

\section{MATERIALS AND METHODS}

The present prospective study was conducted during January 2013 to July 2013 at immunoprophylaxis center and anti-rabies vaccination center (IPC and ARV) of Shri Guru Gobind Singhji Memorial Hospital, a Tertiary Care Hospital which is attached with the Dr. Shankarrao Chavan Government Medical College, Nanded. The 260 dog bite cases were included in our study by purposive sampling. The cases were included in our study who had the telephone facility (either landline or mobile) and who had not any telephone facility, they were excluded. A pretested and predesigned questionnaire was used to elicit the required data pertaining to age, sex, residence (urban/rural), literacy status, occupation, type of $\operatorname{dog}$ (pet/stray, observable/nonobservable, provoked/nonprovoked, rabid status of dog), site of dog bite marks, diagnosis of bite, status of previously immunized against rabies of cases etc., by interviewing. The assessment of treatment compliance of PEP regimen was considered on the basis of ARV regimen (intramuscular injection of ARV on $0,3,7,14,28$ days). The person, who had received all recommended doses of ARV, was considered as completed PEP and who did not receive all recommended doses, was considered as defaulted PEP. Verbal informed consent of all participants was sought after duly informing them about the study.

\section{Protocol for dog bite case management in our hospital}

Once the case presented to outpatient department (OPD), he or she was advised about the local treatment of wound (thorough cleaning under tap water and keeping wound open etc.), ARV dosages as per category of wound, anti-rabies serum for all class three bites and injection TT as per the Guidelines for the PEP by the $\mathrm{WHO}^{[0]}$ and treated accordingly in our OPD. Patients who took treatment were from Nanded city, Nanded district (urban and rural) and from adjacent districts. After experts' advice, of these cases, few wished to follow the same schedule at their native places from government health facilities and remaining continued treatment and received remaining doses of ARV at our OPD.

After the completion of ARV schedule, the cases were contacted telephonically to receive the data regarding the ARV doses using telephone survey method. ${ }^{[17]}$ Data were tabulated and analyzed using statistical software Epi info Version 7 (Atlanta, Georgia, USA) by maintaining confidentiality for percentages, unconditional logistic regression.

\section{RESULTS}

Thus, we had followed $260 \mathrm{dog}$ bite cases. The majority, 30.8\% of dog bite cases were from $\leq 10$ years age group. The median age was 20 and mean \pm standard deviation was $23.46 \pm 17.82$. The similar percentages, $21.2 \%$ of $\operatorname{dog}$ bite cases were from 11 to 20 and 21 to 30 years age group. Only 11 cases were from 41 to 50 years age group. The distribution by sex regarding dog bite cases was more in males $(73.8 \%)$ in comparison with $26.2 \%$ females. The bulk of dog bite cases were from the urban area $(63.8 \%)$ than the rural area $(36.2 \%)$. The $32.7 \%$ dog bite cases had primary school education followed by $21.5 \%$ were illiterate. The occupation profile of dog bite cases showed that $43.8 \%$ were student, $13.1 \%$ were labor, $12.7 \%$ were having job, and so on. We found the most commonly site of bite marks was 70.4\% lower limb in contrast to $25 \%$ upper limb. The maximum dog bite cases, $78.5 \%$ were category III exposure than $21.5 \%$ category II exposure. Only $8.1 \%$ cases had received previously immunized against rabies cases.

The cases were bitten by $70.4 \%$ pet dogs while the remaining by $29.6 \%$ stray dogs. In $73.5 \%$ cases, dogs were observable whereas, in $26.5 \%$ cases, dogs were nonobservable. The bite was provoked in $52.3 \%$ cases and unprovoked in $47.7 \%$ cases. The rabid status of $\operatorname{dog}$ was suspected in $7.3 \%$ cases and not known in $92.7 \%$ cases.

Of 260 dog bite cases, $76.5 \%$ cases were completed PEP as compared to $23.5 \%$ were defaulted PEP. The majority, $22.3 \%$ cases from age group $\leq 10$ years, $56.2 \%$ males, $48.1 \%$ from urban area, $25 \%$ had primary school education, $32.7 \%$ students, $53.8 \%$ had bite mark on lower limb, 58.5 were category III exposure and $70.8 \%$ who had received previously immunization against rabies, were completed PEP. The maximum number of cases, bite due to $54.6 \%$ pet dog, $58.1 \%$ observable dog, $40 \%$ provoked bite, $71.9 \%$ cases who had not known about the rabid status of dog, were completed PEP [Table 1].

The unconditional logistic regression between demographic and exposure factors and treatment compliance to PEP with ARV vaccine among dog bite cases showed nonsignificant results for all dependent variables $(P>0.05)$ except literacy status of dog bite cases, which was found to be independently associated with treatment compliance to PEP $(P<0.05)$ [Table 2].

\section{DISCUSSION}

The present study was carried out to assess treatment compliance of self-reported dog bites cases and to assess associated demographic and exposure factors in our hospital. 


\begin{tabular}{|c|c|c|}
\hline Variables & $\begin{array}{l}\text { Defaulted } \\
\text { PEP }\end{array}$ & $\begin{array}{l}\text { Completed } \\
\text { PEP }\end{array}$ \\
\hline \multicolumn{3}{|l|}{ Age (years) } \\
\hline$\leq 10$ & $22(8.5)$ & $58(22.3)$ \\
\hline $11-20$ & $13(5.0)$ & $42(16.2)$ \\
\hline $21-30$ & $16(6.2)$ & $39(15.0)$ \\
\hline $31-40$ & $04(1.5)$ & $29(11.2)$ \\
\hline $41-50$ & $01(0.4)$ & $10(3.8)$ \\
\hline $51-60$ & $01(0.4)$ & $11(4.2)$ \\
\hline$>61$ & $04(1.5)$ & $10(3.8)$ \\
\hline \multicolumn{3}{|l|}{ Sex } \\
\hline Female & $15(5.8)$ & $53(20.4)$ \\
\hline Male & $46(17.7)$ & $146(56.2)$ \\
\hline \multicolumn{3}{|l|}{ Residence } \\
\hline Rural & $20(7.7)$ & $74(28.5)$ \\
\hline Urban & $41(15.8)$ & $125(48.1)$ \\
\hline \multicolumn{3}{|l|}{ Literacy status } \\
\hline Illiterate & $19(7.3)$ & $37(14.2)$ \\
\hline Primary & $20(7.7)$ & $65(25.0)$ \\
\hline Middle & 05 (1.9) & $30(11.5)$ \\
\hline High school & $08(3.1)$ & $43(16.5)$ \\
\hline Intermediate & $02(0.8)$ & $09(3.5)$ \\
\hline Graduate & $06(2.3)$ & $13(5.0)$ \\
\hline Professional & $01(0.4)$ & $02(0.8)$ \\
\hline \multicolumn{3}{|l|}{ Occupation } \\
\hline Housewife & $04(1.5)$ & $17(6.5)$ \\
\hline Business & $03(1.2)$ & $09(3.5)$ \\
\hline Labor & $08(3.1)$ & $26(10.0)$ \\
\hline Farmer & $06(2.3)$ & $24(9.2)$ \\
\hline Student & $29(11.2)$ & $85(32.7)$ \\
\hline Job & $05(1.9)$ & $28(10.8)$ \\
\hline Dependent & $06(2.3)$ & $10(3.8)$ \\
\hline \multicolumn{3}{|l|}{ Site of bite marks } \\
\hline Head or face & $0(0)$ & 05 (1.9) \\
\hline Upper limb & $16(6.2)$ & 49 (18.8) \\
\hline Lower limb & $43(16.5)$ & $140(53.8)$ \\
\hline Trunk & $0(0)$ & $03(1.2)$ \\
\hline Multiple sites & $02(0.8)$ & $02(0.8)$ \\
\hline \multicolumn{3}{|l|}{ Diagnosis } \\
\hline Category II & $09(3.5)$ & $47(18.1)$ \\
\hline Category III & $52(20.0)$ & $152(58.5)$ \\
\hline \multicolumn{3}{|c|}{ Status of previously immunized cases against rabies } \\
\hline No & $55(21.2)$ & $184(70.8)$ \\
\hline Yes & $06(2.3)$ & $15(5.8)$ \\
\hline \multicolumn{3}{|c|}{ Whether dog was a pet or stray? } \\
\hline Stray & $20(7.7)$ & $57(21.9)$ \\
\hline Pet & $41(15.8)$ & $142(54.6)$ \\
\hline \multicolumn{3}{|c|}{ Whether the dog was observable or nonobservable? } \\
\hline Nonobservable & $21(8.1)$ & $48(18.5)$ \\
\hline Observable & $40(15.4)$ & $151(58.1)$ \\
\hline \multicolumn{3}{|c|}{ Whether the bite was provoked or unprovoked? } \\
\hline Provoked & $32(12.3)$ & $104(40.0)$ \\
\hline Unprovoked & $29(11.2)$ & $95(36.5)$ \\
\hline \multicolumn{3}{|l|}{ Rabid status of dog } \\
\hline Not known & $54(20.8)$ & $187(71.9)$ \\
\hline Suspected & $07(2.7)$ & $12(4.6)$ \\
\hline Total & $61(23.5)$ & $199(76.5)$ \\
\hline
\end{tabular}

PEP = Postexposure prophylaxis
Most of the studies related to treatment compliance to rabies PEP are retrospective studies like that by Mazigo et al. ${ }^{[11]}$ Aworh et al., ${ }^{[12]}$ Bocsan et al., ${ }^{[13]}$ and Kubheka et al. ${ }^{[14]}$ After extensive research, we could find only one prospective study by Shankaraiah et al. ${ }^{[16]}$ about treatment compliance with which could relate the findings of the current study.

Our study findings suggested that majority of cases completed PEP (76.5\%) than defaulted PEP (23.5\%). In the prospective study, on treatment compliance of PEP following dog bite by Shankaraiah et al. ${ }^{[16]}$ the compliance rate for the full course of intramuscular ARV was $60 \%$. The reasons of defaulted PEP could be as asymptomatic person while receiving PEP may be due to varying incubation period, low prevalence of rabies, the irregular regimen which was not on continuous days (Intramuscular Regimen - 0, 3, 7, 14, 28 days), lack of awareness among masses that the rabies is potentially incurable and is only preventable.

In our study, the majority of dog bite cases were males $(73.8 \%)$ and from $\leq 10$ years age group $(30.8 \%)$. Similarly, majority of the bite victims were males $(65.1 \%)$, and most of them were aged below 15 years $(41.4 \%)$ in the study by Shankaraiah et al. ${ }^{[16]}$ These findings were consistent with other retrospective studies on dog bite cases by Behera et al. ${ }^{[2]}$ (71.3\% males and $40.5 \%$ children $<15$ years of age) and Aworh et al. ${ }^{[12]}$ (52.9\% children $<15$ years of age).

The maximum dog bite cases $(78.5 \%)$ were category III exposure than $21.5 \%$ category II exposure and the most common site of bite marks was $70.4 \%$ lower limb, similar to the study by Shankaraiah et al. ${ }^{[16]}(87.5 \%$ on the limbs and $79.0 \%$ had category III exposure) and Kubheka et al. ${ }^{[14]}$ (72\% on lower limbs and slightly lower category III exposure, 43.3\%). Of the dogs implicated for human bites, maximum were pet dogs $(70.4 \%)$ in our study in contrast to the study by Aworh et al. ${ }^{[12]}(52.7 \%$ were stray dogs).

Unconditional logistic regression of demographic and exposure factors with dog bite cases revealed that only literacy status of the dog bite cases was significantly associated with treatment compliance to PEP of ARV vaccine $(P<0.05)$. Rest all the variables did not show any significant association $(P>0.05)$.

The strength of our study was that it was prospective in nature, and not much prospective studies were available to assess the association of demographic and exposure factors with treatment compliance. The major limitation of this study was small sample size which may preclude the statistical significance and being hospital-based study, the cases were self-reported dog bite cases so denominator of dog bite cases could not be determined. The results could not be generalized as those who had no telephonic connection were excluded. Further community-based study is needed with large sample size which would suggest statistical significance for association. 


Table 2: Unconditional logistic regression between demographic and exposure factors and compliance
of ARV vaccine as PEP prophylaxis among dog bite cases

$\mathrm{OR}=$ Odds ratio, $\mathrm{Cl}=$ Confidence interval, $\mathrm{ARV}=$ Anti-rabies vaccine, $\mathrm{PEP}=$ Postexposure prophylaxis

\section{Financial support and sponsorship}

Nil.

\section{Conflicts of interest}

There are no conflicts of interest.

\section{REFERENCES}

1. Sudarshan MK, Kodandaram NS, Venkatesh GM, Mahendra BJ, Ashwath Narayana DH, Parasuramalu BG. Evaluation of a new premedication protocol for administration of equine rabies immunoglobulin in patients with hypersensitivity. Indian J Public Health 2007;51:91-6.

2. Behera TR, Satapathy DM, Mohapatra HH, Sahu AN, Tripathy RM. Evaluation of clinical safety of a new equine rabies immunoglobulin (Inj. VINRIG). APCRI J 2009;10:19-21.

3. Satapathy DM, Reddy SS, Pratap AK, Behera TR, Malini DS, Tripathy RM, et al. Drop-out cases in IDRV: A cause of concern. APCRI J 2010;12:40-1.

4. Aghahowa SE, Ogbevoen RN. Incidence of dog bite and anti-rabies vaccine utilization in the, University of Benin Teaching Hospital, Benin City, Nigeria: A 12-year assessment. Vaccine 2010;28:4847-50.

5. Kale KM, Wadhva SK, Aswar NR, Vasudeo ND. Dog bites in children. Indian J Community Med 2006;31:24-5.

6. Sharma AL, Bhuyar PA, Bhawalkar JS, Pawar SN. Profile of management of animal bite cases among rural population in district Pune, Maharashtra. Indian J Public Health 2007;51:62-3.

7. Vinay M, Subhash BP, Anil KK, Harish BR, Mahendra BJ, Poornima S, et al. Profile of rabies immunoglobulin recipients of anti rabies clinic, MIMS, Mandya. APCRI J 2010;12:37-9.
8. Parviz S, Chotani R, McCormick J, Fisher-Hoch S, Luby S. Rabies deaths in Pakistan: Results of ineffective post-exposure treatment. Int $\mathrm{J}$ Infect Dis 2004:8:346-52.

9. Park K. Park's Textbook of Preventive and Social Medicine. $22^{\text {nd }}$ ed. Jabalpur, India: Banarsidas Bhanot Publication; 2013. p. 251-6.

10. Bhalla S, Mehta JP, Singh A. Knowledge and practice among general practitioners of Jamnagar city regarding animal bite. Indian J Community Med 2005;30:94-6.

11. Mazigo HD, Okumu FO, Kweka EJ, Mnyone LL. Retrospective analysis of suspected rabies cases reported at bugando referral hospital, Mwanza, Tanzania. J Glob Infect Dis 2010;2:216-20.

12. Aworh MK, Nwosuh $\mathrm{Cl}$, Ajumobi OO, Okewole PA, Okolocha EC Akanbi BO, et al. A retrospective study of rabies cases reported at Vom Christian Hospital, Plateau State, Nigeria, 2006-2010. Niger Vet J 2011;32:366-70.

13. Bocsan IS, Brumboiu I, Coman A, Tarba R, Zanc V, Mihaiu M. Rabies surveillance in the rural population of Cluj County, Romania. Rural Remote Health 2005;5:431.

14. Kubheka V, Govender P, Margot B, Kuonza LR. Dog bites and human bites in the Uthungulu district of KwaZulu-Natal province, 2008-2010: A review of surveillance data. South Afr J Epidemiol Infect 2013;28:33-40.

15. Moran GJ, Talan DA, Mower W, Newdow M, Ong S, Nakase JY, et al. Appropriateness of rabies postexposure prophylaxis treatment for animal exposures. Emergency ID Net Study Group. JAMA 2000;284:1001-7.

16. Shankaraiah $\mathrm{RH}$, Rajashekar RA, Veena V, Hanumanthaiah AN Compliance to anti-rabies vaccination in post-exposure prophylaxis Indian J Public Health 2015;59:58-60.

17. Thulasingam M, Cheriyath PK. Telephone survey as a method of data collection in South India. Indian J Community Med 2008;33:268-70. 